\title{
A FORMAÇÃO INICIAL DE PROFESSORES EM NİVEL MÉDIO (CURSO NORMAL) E A INCLUSÃO ESCOLAR
}

Neusete Machado Rigo ${ }^{(*)}$ Roseli Andreia Sackvil ${ }^{(*)}$ Eloísa Maria Womer ${ }^{* * *}$

\section{O CURSO NORMAL E A FORMAÇÃO INICIAL DE PROFESSORES}

O Curso Normal surgiu no Brasil durante o século XIX como espaço para a formação de professores que atuariam na educação primária e secundária. Embora não seja possível fazer aqui uma retomada histórica dos caminhos que constituíram a identidade do Curso Normal no Brasil, podemos dizer que até o ano de 1881 dezenas de Escolas Normais foram criadas em todo o país, inclusive no Rio Grande do Sul, em 1870 (ROMANELLI, 1985). Segundo a Lei Orgânica do Ensino Normal, instituída pelo Decreto 8.530, em 1946, a Escola Normal tinham como finalidade: 1) Prover a formação do pessoal docente necessário às escolas primárias; 2) Habilitar administradores escolares destinados às mesmas escolas; e 3) Desenvolver e propagar os conhecimentos e técnicas relativas à educação da infância (BRASIL, 1946).

No entanto, a construção de uma política nacional para a formação de professores no Brasil só se fortaleceu em 1996 com a Lei 9.394/96, Lei de Diretrizes e Bases da educação (LDB/96), que instituiu a obrigatoriedade da formação docente em nível superior para a atuação na educação básica, sendo obtida em curso de Licenciatura, porém admitindo também formação em nível médio, ofertada pelo Curso Normal:

Art. 62. A formação de docentes para atuar na educação básica far-se-á em nível superior, em curso de licenciatura plena, admitida, como formação mínima para o exercício do magistério na educação infantil e nos cinco primeiros anos do ensino

\footnotetext{
${ }^{(*)}$ Docente na Universidade Federal da Fronteira Sul (UFFS) - campus Cerro Largo/RS. Integrante do Grupo de Pesquisa Políticas Públicas Educacionais e Práticas Pedagógicas (GPPPEPP/UFFS) e do Grupo de Pesquisa em Políticas e Práticas de Inclusão (GPPPIN/UFFS). Doutora em Educação. Coordenadora do Projeto de Pesquisa A escola inclusiva como espaço de formação para a potencialização da inclusão social (Edital 523/UFFS/2017-PIBICEM/CNPq). E-mail: neuseterigo@gmail.com.

${ }^{(* *)}$ Estudante do Curso Normal do Instituto Estadual de Educação Visconde de Cairu - Santa Rosa/RS. Bolsista do CNPq (Edital 523/UFFS/2017-PIBIC-EM/CNPq). E-mail: roselisackvil@ gmail.com.

${ }^{(* * *)}$ Professora do Curso Normal do Instituto Estadual de Educação Visconde de Cairu - Santa Rosa/RS. Pós-graduada em Educação. Co-orientadora do projeto CNPq (Edital 523/UFFS/2017-PIBIC-EM/CNPq). E-mail: isawomer@yahoo.com.br.
} 
fundamental, a oferecida em nível médio, na modalidade normal (Grifos nossos. BRASIL, 2017).

A exigência da formação em nível superior é afirmada no artigo 87 da LDB/96, no parágrafo $4^{\circ}$, do inciso $4^{\circ}$, para ser cumprida até o fim da Década da Educação (1996-2006), quando finalmente só seriam admitidos professores com habilitação em nível superior. Muitos questionamentos emergiram dessa regulamentação quanto à continuidade do Curso Normal, no entanto, o debate profícuo sobre essa questão culminou na Conferência Nacional de Educação Básica (CONAE), realizada em Brasília, em 2010, que discutiu e aprovou a permanência da formação em nível médio como requisito mínimo para a docência nos anos iniciais e na educação infantil.

Considerando que as Escolas Normais formam professores/as para atuar na educação infantil e nos anos iniciais, e a instituição da Política Nacional de Educação Especial na Perspectiva da Educação Inclusiva/PNEEPEI ${ }^{1}$, em 2008 , esse texto apresenta resultados de uma pesquisa que se deteve em analisar a formação inicial de professores proporcionada pelo Curso Normal em uma perspectiva inclusiva. A referida pesquisa foi realizada em uma escola pública localizada na região Noroeste do estado do Rio Grande do Sul.

A metodologia empreendida consistiu em uma pesquisa qualitativa, utilizando-se da análise documental do Projeto Político-Pedagógico (PPP) da escola e dos Planos de Estudos (PE) do Curso Normal, e ainda, de 08 dos 60 relatórios das Práticas Pedagógicas (PP) ${ }^{2}$ realizadas pelos/as alunos/as do $1^{\circ}$ ao $3^{\circ}$ ano, selecionados para a análise. $\mathrm{O}$ critério tomado para a seleção destes foi a clareza e a intensidade da reflexão expressa na escrita do relato. Os dados levantados foram analisados tomando os conceitos experiência (Larrosa) e normalidade/anormalidade (Foucault), os quais possibilitaram refletir sobre as compreensões que os/as alunos/as apresentaram sobre a inclusão escolar.

O objetivo dessa escrita é analisar a formação inicial que o currículo do Curso Normal está oferecendo em relação à inclusão escolar. Fazemos em especial uma análise sobre os relatórios das Práticas Pedagógicas realizadas pelos/as alunos/as, a partir do seguinte questionamento: que reflexões em relação à inclusão escolar a formação proporcionada pelo Curso Normal está

\footnotetext{
${ }^{1}$ Fazemos uso da sigla PNEEPEI como referência à Política Nacional de Educação Especial na Perspectiva da Educação Inclusiva/2008.

${ }^{2}$ As Práticas Pedagógicas são atividades de docência que os/as alunos/as do Curso Normal realizam nas turmas dos anos iniciais e educação infantil para cumprir a exigência legal de 400 horas de práticas de ensino.
} 
possibilitando aos/às alunos/as durante as Práticas Pedagógicas desenvolvidas nas turmas dos anos iniciais e na educação infantil?

O texto apresenta inicialmente uma contextualização do currículo do Curso Normal em relação à inclusão escolar. Para isso, utiliza documentos da escola (PPP e PE) para analisar como a escola e o Curso Normal articulam a atual política nacional de inclusão no seu currículo, indicando uma formação inicial preocupada com a inclusão do público da educação especial. Na sequência, discute a partir das compreensões dos/as alunos/as sobre a inclusão das crianças com deficiências nas turmas comuns, explorando os registros e as reflexões apresentadas nos seus relatórios das Práticas Pedagógicas. Essa discussão estabelece reflexões sobre duas perspectivas observadas nos relatos dos/as alunos/as, sob as quais pode-se situar a inclusão escolar: uma que trata a anormalidade como incapacidade, e outra, que aponta a experiência como possibilidade para o ensino e para a convivência com o sujeito com deficiências.

\section{A POLÍTICA NACIONAL DE INCLUSÃO ESCOLAR E O CURRÍCULO DO CURSO NORMAL}

A PNEEPEI, apresentada à sociedade brasileira em 2008, pelo Ministério da Educação, através da Secretaria de Educação Especial, define que as crianças com deficiências sejam matriculadas nas escolas comuns ${ }^{3}$, como forma de garantir seu direito à educação. Este preceito segue as discussões e acordos internacionais definidos em grandes conferências, tais como: Declaração Mundial de Educação para Todos (Jomtien/1990), Declaração de Salamanca (Espanha, 1994), Declaração da Guatemala (Guatemala/1999) e a Convenção sobre os Direitos das Pessoas com Deficiência (Nova Iorque/2006). Como signatário destas, o Brasil emitiu alterações na legislação nacional, inclusive na Constituição Federal/88, reafirmando a posição assumida mundialmente. Este cenário mundial e nacional se confirma pela PNEEPEI que representa a posição do Brasil em relação à inclusão das pessoas com deficiências na escola comum.

Nessa perspectiva, o MEC segue o compromisso brasileiro firmado, homologando em 2009, as Diretrizes Operacionais para o Atendimento Educacional Especializado na Educação Básica, modalidade educação especial, esclarecendo que a concepção de Educação Especial adotada na perspectiva da educação inclusiva, busca "superar a visão do caráter substitutivo da Educação Especial ao ensino comum, bem como a organização de espaços educacionais separados para

\footnotetext{
${ }^{3}$ Segundo a legislação vigente (Parecer CNE 4/2009), o termo 'escola comum' ou 'classe comum' caracteriza a escola regular destinada à todos os estudantes que possuam ou não deficiências, e é utilizado para diferenciar as 'escolas especiais', destinadas exclusivamente àqueles que possuem deficiências.
} 
alunos com deficiência" (BRASIL, 2013, p. 279). Nessa perspectiva, os alunos com deficiências devem ser matriculados nas escolas comuns e não mais em escolas especiais.

A partir dessas orientações legais muitos sistemas de ensino passaram a contemplar em suas diretrizes e propostas pedagógicas uma perspectiva de educação inclusiva que impulsionou as escolas a elaborarem Projetos Político-Pedagógicos preocupados com a inclusão das crianças com deficiências. No Estado do Rio Grande do Sul, por exemplo, a Secretaria Estadual de Educação apresentou, em 2014, as Diretrizes orientadoras para a rede estadual de ensino no Rio Grande do Sul, referentes à Educação Especial na perspectiva da Educação Inclusiva. No documento em que estas são apresentadas destaca-se o caminho trilhado pela rede estadual em resposta à sociedade gaúcha para a formulação de uma educação que garanta acesso e permanência dos alunos com deficiência no ensino regular (RIO GRANDE DO SUL, 2014). A proposta “considera um plano comum a todas as escolas e, ao mesmo tempo, a necessidade do envolvimento de cada espaço escolar, a partir de suas peculiaridades" (RIO GRANDE DO SUL, 2014, p. 4). Ainda, enfatiza que as mudanças se fazem de modo gradativo dependendo tanto de normas e documentos normatizadores, quanto do engajamento daqueles que atuam nas coordenações dos processos educativos.

Todavia, trata-se de um engajamento que pode produzir propostas que se traduzam em práticas de ensino que possibilitem a construção de uma educação que torne as escolas mais inclusivas. Dessa forma, as análises que fizemos sobre os efeitos da PNEEPEI e das normatizações e orientações do sistema estadual de ensino do Rio Grande do Sul, sobre o currículo do Curso Normal, indicam que essas orientações legais estão presentes no processo de formação inicial de professores para os anos iniciais e educação infantil. Encontramos nos documentos da escola Projeto Político-Pedagógico (PPP) e Plano de Estudos (PE) -, indicativos da inclusão escolar perpassando a formação à docência no Curso Normal, e por isso, podemos dizer que o currículo dessa escola contempla na formação inicial o preparo dos/as alunos/as para trabalhar com crianças que possuem deficiências. Porém, estamos considerando que a escola e o curso encontram-se em processo de adequação à atual política de inclusão escolar e de formação inicial necessária para sua efetivação. Mesmo assim, sua caminhada já indica sinais de aproximação à educação inclusiva. No quadro abaixo, trazemos alguns excertos dos planejamentos da escola que norteiam o currículo do Curso Normal em direção à inclusão escolar. 


\section{Quadro 1: Documentos escolares}

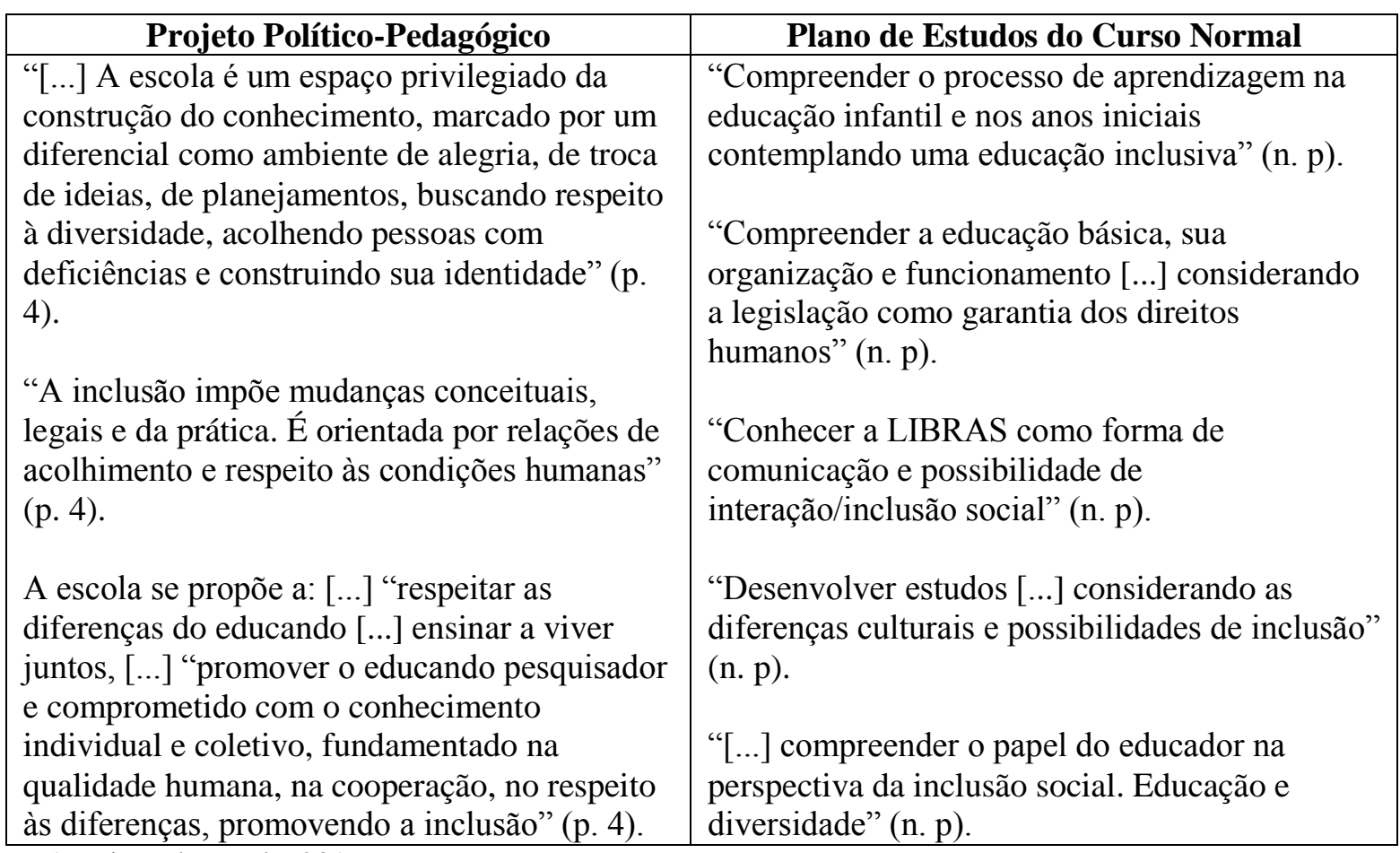

Fonte: Arquivos da escola, 2017.

Constatamos que a escola aponta em seu PPP o protagonismo de um espaço de formação segundo valores humanos que contemplam o respeito à diversidade e à inclusão das pessoas com deficiências na sociedade. De certa forma, esse referencial político-pedagógico apresenta-se como uma tentativa de "responder" aos compromissos que o Brasil assumiu mediante sua inserção nos movimentos inclusivos internacionais para a construção de uma escola pública e democrática. Isso significa que o Estado está assumindo a educação de crianças com deficiências que durante muito tempo ficaram fora da escola e, por isso, foram acolhidas em instituições especializadas e/ou assistenciais.

Observamos que o PPP defende a escola como "[...] um espaço privilegiado da construção do conhecimento, [...] buscando respeito à diversidade, acolhendo pessoas com deficiências [...]" (PROJETO..., 2017, p. 4), como forma de afirmar seu compromisso com a democratização da sociedade. Incluir as pessoas com deficiências na escola comum é uma forma de ampliar a democratização da escola. De acordo com Gallo (2017, p. 41), o maior desafio para a educação brasileira no século XXI é ampliar o acesso à educação pública como espaço de formação democrática e social, em sistemas públicos de ensino com qualidade social, desde a educação infantil até a universidade. Abrir a escola para a diversidade e para as diferenças significa a possibilidade de educar para a coletividade, para a vida pública e democrática. 
A inclusão escolar sustenta-se na perspectiva dos direitos humanos, reconhecendo o direito de todos à educação como possibilidade para o fortalecimento da inclusão social. Porém, a escola reconhece que "a inclusão impõe mudanças conceituais" e depende de práticas que orientem "[...] relações de acolhimento e respeito às condições humanas" (PROJETO... 2017, p. 4). Nesse sentido, ela apresenta em seus Planos de Estudos uma visão clara sobre o papel do professor e da escola em relação à inclusão, que perpassa pela compreensão do "[...] papel do educador na perspectiva da inclusão social", das relações entre "educação e diversidade" para construir espaços de "pluralidade no âmbito da escola" (PLANO..., 2017, n.p). No entanto, essas mudanças dependem das concepções filosóficas e epistemológicas dos/as professores/as para romper com os padrões de normalidade que geralmente constituem os currículos e orientam as práticas de ensino em sala de aula. Há que se considerar que grande parte dos/as professores/as não teve em sua formação inicial qualquer reflexão ou estudo acerca da inclusão de crianças com deficiência nas escolas e classes comuns. Isso faz com que o desafio da formação de professores se constitua em um processo coletivo, entre professores do curso e alunos/as, em uma constante articulação entre teoria e prática, entre o que se aprende/se ensina no curso e o que se vive nas escolas, no chão das salas de aula.

Nesse sentido, nos parece animador observar que o currículo do Curso Normal dessa escola articula objetivos escolares e prática pedagógica para promover uma formação inicial à docência conectada com as políticas nacionais de inclusão, quando se propõe a "compreender a educação básica, sua organização e funcionamento [...] considerando a legislação como garantia dos direitos humanos” (PLANO..., 2017, n.p). Contudo, essa formação em nível médio não dá conta do desafio da inclusão de todos na escola, mas pode representar o início de uma sólida formação que deverá ser ampliada ao longo da carreira docente, em curso de licenciatura ou em processos de formação continuada. Nessa perspectiva, Tardif (2017) nos diz que o dever dos professores de hoje é o contínuo aperfeiçoamento:

[...] hoje, o mais importante é a formação continuada e o desenvolvimento profissional dos professores. Os docentes de hoje precisam aprender ao longo de toda a vida, devem transformar e ajustar seus conhecimento e competências em função da evolução da sociedade e dos públicos escolares (TARDIF, 2017, p. 63).

Ainda, Tardif complementa afirmando que o aprendizado da docência não se limita a conhecimentos teóricos, porque "um profissional é aquele que possui saberes práticos capazes de agir sobre a realidade e transformá-la" (2017, p. 63). Esses saberes práticos são aqueles que a experiência da docência proporciona ao longo da sua vida nas escolas e, principalmente, nas salas de aula, no processo de ensino com seus alunos. Assim, ao vivenciar processos inclusivos nas 
escolas, em especial nos anos iniciais e educação infantil, durante as Práticas Pedagógicas e Estágios Curriculares, previstos pela matriz do Curso Normal, os/as alunos/as são provocados/as a refletir sobre a inclusão, como relata uma aluna em seu relatório ${ }^{4}$ das Práticas Pedagógicas:

Estas práticas de observação constituem uma significativa experiência, pois é através delas que o aluno vivencia a realidade da sala de aula, pois proporcionam a aquisição de conhecimentos que servirão de embasamento para a prática em sala de aula, porém é necessário realizar reflexões críticas sobre aquilo que foi observado (R1).

A formação que o currículo da escola proporciona aos/às alunos/as do Curso Normal pode ser compreendida como um esforço inicial para introduzir pressupostos filosóficos básicos sobre a inclusão que, mesmo sendo insuficientes por serem abordados de maneira dispersa entre os componentes curriculares, podem levar os/as alunos/as a "compreender o processo de aprendizagem na educação infantil e nos anos iniciais contemplando uma educação inclusiva" (PLANO..., 2017, n. p.).

Desta forma, na seção seguinte discutimos alguns sinais, pequenas centelhas de experiências produzidas pelos/as alunos/as do Curso Normal, expressas pelas suas reflexões nos relatórios das Práticas Pedagógicas realizadas em turmas de alunos/as com deficiências. Considerando que essas práticas objetivam proporcionar reflexões sobre experimentações pedagógicas e contribuir para que os/as alunos/as construam seu fazer pedagógico (PLANO..., 2017, n. p.), nosso objetivo na próxima sessão é refletir a partir das suas manifestações sobre a experiência produzida por estas, como possibilidade para romper com a ideia de normalidade como guia para a construção dos processos de ensino envolvendo alunas/os com deficiências.

\section{AS PRÁTICAS PEDAGÓGICAS: EXPERIÊNCIAS QUE PRODUZEM IMPRESSÕES SOBRE OS/AS ALUNOS/AS COM DEFICIÊNCIAS}

As Práticas Pedagógicas previstas no currículo do Curso Normal são distribuídas de acordo com os trimestres anuais do calendário letivo e vivenciadas pelos/as alunos/as do $1^{\circ}, 2^{\circ}$ e $3^{\circ}$ anos. São desenvolvidas em turmas dos anos iniciais e da educação infantil em escolas da rede de educação básica do município e da região, e são acompanhadas pelos/as professores/as que atuam nos diversos componentes curriculares do curso: Libras, Língua Portuguesa, Psicologia, Didática Geral, Didática da Educação Física, Didática da Arte e Didática do Ensino Religioso. Conforme os Planos de Estudos, essas práticas têm como objetivos:

\footnotetext{
${ }^{4}$ Para utilização dos dados obtidos nos relatórios, os identificamos como: R1, R2, R3, R4, R5, R6, R7, R8.
} 
[...] aprofundar a reflexão sobre as práticas pedagógicas vivenciadas na Educação Infantil e nos anos iniciais do ensino fundamental com ênfase na Educação Especial; realizar estudos de campo com orientação e experimentação pedagógica nas Classes de Aplicação em situação real de sala de aula, para construir seu fazer pedagógico num processo de ação-reflexão-ação; vivenciar experiências de planejamento, de execução e avaliação do trabalho de regência de classe para conhecer, refletir e construir alternativas na sua ação pedagógica (Grifos nossos. PLANO..., 2017, p. 7).

Esclarecemos que as Práticas Pedagógicas, sob as quais tecemos reflexões nesse estudo, envolvem alunos/as com deficiências e possuem diferentes propostas para cada ano do Curso. A modalidade de Prática Pedagógica prevista para o $1^{\circ}$ ano consiste em atividades de observação em sala de aula e elaboração de relatório. Os aspectos a serem observados foram indicados pelas professoras titulares do curso e apontavam para o planejamento e as dinâmicas de aula desenvolvidas pela professora, a socialização e integração dos alunos, as condições de apoio à deficiência do aluno, e a qualidade dos espaços pedagógicos e dos processos de aprendizagem. Após estas observações os/as alunos/as produziram um relatório reflexivo, e em um determinado momento as socializaram com os colegas de turma.

Pela pesquisa realizada nos relatórios das alunas do $1^{\circ}$ ano do curso, observamos que o momento de socialização foi muito significativo, principalmente, pelo diálogo provocado a partir das diferentes experiências vividas. Segundo uma aluna, isso foi:

[...] extremamente positivo, pois possibilitou uma troca de experiências e aprendizados [...]. Foi um momento de socialização que permitiu conhecer realidades diferentes de escolas e de metodologias utilizadas pelas professoras titulares como "exemplos positivos que servem como inspiração para a promoção da inclusão pelos alunos nas práticas em sala de aula (R1).

No $2^{\circ}$ ano, as Práticas Pedagógicas eram diversas, mas em especial destacamos a observação e monitoria realizadas em aulas de Educação Física. A proposta do componente curricular de Didática da Educação Física consistia no acompanhamento a uma turma que possuía aluno/s com deficiência, e na sequência os/as alunos/as deveriam planejar e desenvolver uma aula para toda a turma, considerando a presença desse/a aluno/a. Durante a observação, a tarefa dada era verificar “como o aluno com deficiência da turma estava sendo incluído nas aulas de educação física [...] se contava com um plano de aula separado, e quais as suas dificuldades e a sua deficiência" (R1).

No $3^{\circ}$ ano, as Práticas Pedagógicas relacionadas à inclusão das crianças com deficiências apresentavam novas etapas de observações e práticas de ensino desenvolvidas. Sempre acompanhadas de uma etapa final que consistia na elaboração de um relatório, teciam reflexões 
sobre o contexto dos/as alunos/as com deficiência na turma, e também sobre os procedimentos pedagógicos adotados pela professora titular.

Pelas análises dos relatórios das Práticas Pedagógicas identificamos duas perspectivas sobre o processo de inclusão escolar e a docência: a) a anormalidade como incapacidade; e b) a experiência como possibilidade para o ensino e para a convivência com o sujeito com deficiências.

Dos 60 relatórios analisados, selecionamos excertos de 08 relatórios que expressam essas perspectivas, para na sequência refletirmos sobre elas:

\section{Quadro 2: Relatórios das Práticas pedagógicas}

\begin{tabular}{|l|l|}
\hline \multicolumn{1}{|c|}{ A anormalidade como incapacidade } & \multicolumn{1}{c|}{ A experiência como possibilidade } \\
\hline $\begin{array}{l}\text { (Percebi) alunos com dificuldade de } \\
\text { concentração em aula, [...] dificuldades em } \\
\text { terminar um livro, [...] falam excessivamente } \\
\text { e têm dificuldades para realizar atividades em } \\
\text { silêncio, parecem não ouvir quando o } \\
\text { chamam [...] (R2). }\end{array}$ & $\begin{array}{l}\text { Aprendi que mesmo tendo dificuldades físicas a } \\
\text { criança tem capacidade de aprender, mas com } \\
\text { suas limitações que podem ser desenvolvidas com } \\
\text { muito trabalho (R3). }\end{array}$ \\
\hline $\begin{array}{l}\text { Demora (o aluno) muito para iniciar uma } \\
\text { tarefa que exija longo esforço, [...] possui } \\
\text { dificuldades em seguir instruções, em iniciar } \\
\text { uma atividade (R5). }\end{array}$ & $\begin{array}{l}\text { Observei que tendo em sala de aula um aluno com } \\
\text { limitações, as crianças começam a perceber que } \\
\text { ser diferente é normal e que todos nós também } \\
\text { possuímos limitações e que cada um com sua } \\
\text { diferença torna o mundo mais humano, mais legal } \\
\text { (R6). }\end{array}$ \\
\hline $\begin{array}{l}\text { Ficava (o aluno) olhando para os lados, } \\
\text { rabiscando o caderno, ou mexendo nos } \\
\text { materiais e colocando-os na boca (R8). }\end{array}$ & $\begin{array}{l}\text { Para a trabalhar com alunos inclusos é preciso } \\
\text { maior cuidado, também é preciso paciência, pois } \\
\text { eles não têm tanta facilidade quanto os outros } \\
\text { (R7). }\end{array}$ \\
\hline $\begin{array}{l}\text { Percebi que o [...] possui um atraso muito } \\
\text { significativo no conhecimento, se comparado } \\
\text { com as outras crianças (R4). }\end{array}$ & $\begin{array}{l}\text { Estas práticas de observação constituem uma } \\
\text { significativa experiência, [...] é através delas que o } \\
\text { aluno (do Curso Normal) vivencia a realidade da } \\
\text { sala de aula, pois proporcionam a aquisição de } \\
\text { conhecimentos que servirão de embasamento para } \\
\text { a prática em sala de aula, porém é necessário } \\
\text { realizar reflexões críticas sobre aquilo que foi } \\
\text { observado (R1). }\end{array}$ \\
\hline
\end{tabular}

Fonte: Relatórios das Práticas Pedagógicas do Curso Normal, 2018.

Constatamos que a perspectiva da anormalidade como incapacidade é preponderante e confirma pesquisas (RIGO, 2015, p. 39) realizadas que apontam a "anormalidade", ou seja, a deficiência, como o problema, ou seja, a criança com deficiência é um problema porque "não aprende como as demais", "não acompanha a turma", "não atende às normas".

Para compreendermos como isso se dá, buscamos nos estudos de Michel Foucault, especialmente quando ele discute a noção de norma, no livro Segurança, Território e População (2008), a compreensão da anormalidade como efeito da norma, esta que define um modelo, capaz de exercer um poder que identifica e legitima o que é normal e o que é anormal. Segundo Foucault 
(2008), a norma foi fundamental nas sociedades disciplinares para fixar o que era considerado normal. A partir dela era possível identificar e separar o que era considerado como normal ou não, e se colocava em funcionamento um processo de normalização para "tornar as pessoas, os gestos, os atos, conformes a esse modelo, sendo normal precisamente quem é capaz de se conformar a essa norma e o anormal quem não é capaz” (FOUCAULT, 2008, p. 75). Desta forma, a norma não teria por função excluir ou rejeitar, mas ao contrário, como Foucault (2010, p. 43) nos diz, "ela está sempre ligada a uma técnica positiva de intervenção e de transformação, a uma espécie de poder normativo" que conduz os sujeitos ou uma população a conformar-se à ela. Assim, podemos compreender que o poder da norma que afeta os processos de inclusão não pretende excluir, ao contrário, incluir significa operar um processo de normalização do sujeito, com a pretensão de aproximá-lo da normalidade.

Nas sociedade de seguridade, emergentes a partir do século XVII, quando surge o problema da população e a necessidade de conduzir as suas condutas sob outras formas, diferentemente do que se fazia na Antiguidade por intermédio do poder soberano (do rei), Foucault explica um funcionamento diferente da norma. A identificação de diferentes "curvaturas de normalidade" a partir da flexibilização daquilo que nas sociedades disciplinares marcava a segurança, permitiu nas sociedade de seguridade que o "normal" fosse determinado de maneira diferente no interior de cada grupo. Nesse modelo de sociedade, a normalidade é definida a partir de regras que se dão no decurso de um problema, ou seja, a norma não se dá a priori, como nas sociedades disciplinares, mas a partir de um conjunto de saberes e poderes que afirmam um grau de aceitabilidade da normalidade em um contexto. Isso faz com que em algum momento ou situação, algo considerado anormal seja normal em outro contexto. Assim, podemos ver que na atualidade, o "normal" e o "anormal" não seguem regras fixas predeterminadas, mas alteram-se segundo "curvaturas de normalidade", do que é considerado ou não normal em um grupo ou em um determinado contexto.

Sob esse modo de conceber a anormalidade é que a inclusão das pessoas com deficiências, tanto na sociedade quanto na escola é aceitável, ou seja, no contexto atual a inclusão é considerada normal, ou pelo menos isso vem se intensificando sob diversos argumentos sustentados pela ordem da ética e dos direitos humanos. Afinal, há um conjunto de discursos que provém de diferentes lugares, seja do campo jurídico, dos direitos humanos, da pedagogia, da mídia, que nos conduzem a aceitar a inclusão das pessoas com deficiências na escola comum como normalidade, a exemplo do discurso midiático que ouvimos com frequência de que "ser diferente, é ser normal".

No entanto, geralmente constatamos que a inclusão da "anormalidade" na escola é considerada normal desde que seja aproximada da normalidade, mediante mudanças nos currículos 
e nas posturas dos sujeitos envolvidos (família, escola). Os apelos para a inclusão passam pela ampliação e intensificação dos mecanismos de normalização dos/as alunos/as com deficiências (os/as "anormais"), a fim de que se aproximem da normalidade e se integrem aos processos de ensino destinados aos demais (os/as "normais").

Sob essa perspectiva de normalização, observamos em alguns relatórios dos/as alunos/as do Curso Normal, manifestações que inferiorizam a criança com deficiência, porque ela "[...] demora muito para iniciar uma tarefa que exija longo esforço, [...] possui dificuldades em seguir instruções, em iniciar um atividade" (R5); fica "[...] olhando para os lados, rabiscando o caderno, ou mexendo nos materiais e colocando-os na boca" (R8); e ainda, a comparam com os colegas da turma, ou seja, tomam a "normalidade" como referência, como disse uma aluna em seu relatório: "[...] percebi que o [...] possui um atraso muito significativo no conhecimento, se comparado com as outras crianças" (R4).

Outra perspectiva observada nos relatórios indica que as Práticas Pedagógicas, tratando-se de práticas inclusivas, podem ser compreendidas como experiências vividas nos processos de ensino. Podemos ensejar que as experiências desses/as alunos/as, estão para além de serem simplesmente um "experimento pedagógico", mas muito próximas daquilo que Larrosa (2017) define como algo raro. Larrosa (2017) explica a experiência como algo difícil de acontecer, porque ela acontece no sujeito, ela não passa diante dele, mas ela é aquilo que se passa no sujeito, que o toca, e o torna o local da experiência. Segundo esse autor, "a cada dia se passam muitas coisas, porém, ao mesmo tempo, quase nada acontece" (2017, p. 18). Ele nos alerta que a experiência produzida, e só ela, será capaz de provocar a mudança e transformar o sujeito, por isso a pedagogia e a didática devem dar lugar à experiência. Ela é que dá sentido à educação e não a verdade (LARROSA, KOHAN, 2014, p.7). Não é aquilo que nos é dado como verdade, ou o que tomamos como verdade, que tem sentido para nossa vida, mas sim, aquilo que se passa em nós como um acontecimento que nos transforma. Assim, corroborando Larrosa, podemos dizer que a experiência é que forma/transforma o/a professor/a:

A experiência não é uma realidade, uma coisa, um fato, não é fácil de definir nem identificar, não pode ser objetivada, não pode ser produzida. [...] A experiência é algo que (nos) acontece e que às vezes treme, ou vibra, algo que nos faz pensar, algo que nos faz sofrer ou gozar, algo que luta pela expressão, e que às vezes, algumas vezes, quando cai em mãos de alguém capaz de dar forma a esse tremor, então somente então, se converte em canto (LARROSA, 2017, p. 10). 
Por isso, ao tomarmos as reflexões sobre as Práticas Pedagógicas vivenciadas pelos/as alunos/as do Curso Normal, podemos observar algumas nuances sobre suas experiências vividas nas salas de aulas com alunos/as com deficiências. Essas são possibilidades para a produção de uma crítica acerca dos saberes pedagógicos, disciplinares e curriculares que perpassam sua formação inicial. Ainda, essas práticas podem ser consideradas como espaço e tempo que estão compondo a formação inicial como possibilidade para que os/as alunos/as possam se dar conta das experiências vividas ao longo do processo formativo que o curso lhes está proporcionando. As Práticas Pedagógicas são espaços para viver a experiência da docência, e são também, tempo para pensar, conversar, ouvir, relembrar, rever e fazer da vivência algo mais do que uma prática pontual, ou seja, fazer uma transformação de si.

Nessa perspectiva, podemos nos valer do pensamento de Tardif (2008, p. 53) ao dizer que a “prática pode ser vista como um processo de aprendizagem através do qual os professores retraduzem sua formação". Isso porque, os saberes pedagógicos e os saberes curriculares proporcionados pelo Curso Normal, passam por um processo crítico e reflexivo quando os/as alunos/as se deparam com a prática da docência e o exercício da escrita sobre ela. A reflexão será então, imprescindível para a experiência, e melhor será se realizada entre os sujeitos que partilham os mesmos espaços e vivências similares. Por isso, Tardif (2008) insiste na importância das experiências serem partilhadas entre os/as professores/as:

É através das relações com os pares, e, portanto, através do confronto entre os saberes produzidos pela experiência coletiva dos professores, que os saberes experienciais adquirem uma certa objetividade: as certezas subjetivas devem ser, então, sistematizadas a fim de se transformarem num discurso da experiência capaz de informar ou de formar outros docentes e de fornecer uma resposta a seus problemas (TARDIF, 2008, p. 52).

Nessa direção, no R1 a aluna avalia a necessidade e a importância de após a realização das Práticas Pedagógicas estabelecer diálogos com os/as colegas e as professoras para refletir sobre a experiência vivida. Embora Larrosa (2011) diga que seria impossível relatar uma experiência, porque ela é inenarrável e intraduzível, porque ela não se dá fora do sujeito como um "experimento", como algo "empírico", o simples fato dos/as alunos/as relatarem o que mudou em seu pensamento com a convivência com o aluno com deficiência, indica que se produziu uma experiência. Quando uma aluna relata que "foi possível perceber que todos os alunos são capazes" (R1), está dizendo sobre uma mudança que ocorreu consigo, uma experiência que é singular e não poderá ser narrada, e também nunca se repetirá em outra situação, sempre será diferente. 
Com as leituras das reflexões dos/as alunos/as nos seus relatórios, podemos dizer que as experiências vivenciadas vão pouco a pouco constituindo uma subjetividade docente. Porém, nos questionamos sobre as possibilidades da prática e da reflexão destituírem a normalidade como pressuposto para as práticas de inclusão. Ou seja, até que ponto as experiências vividas pelos/as alunos/as do Curso Normal são potenciais para práticas inclusivas que não estejam tão preocupadas com a normalização dos sujeitos com deficiências como geralmente ocorre nos processos de inclusão escolar?

Como vimos nos relatos das práticas pedagógicas a deficiência aparece como um problema porque o/a aluno/a apresenta dificuldades para aprender ou para conformar-se às regras escolares. Comparado aos demais a anormalidade representa incapacidade e muitas vezes atrapalha, perturba e impede a normalidade tão desejada. No entanto, alguns relatos refletem sobre um encontro com o Outro - o sujeito com deficiência - que indica uma experiência vivida, e permite compreender o/a aluno/a com deficiências como um sujeito de potencialidades. A partir disso podemos nos valer do pensamento de Pagni (2015), quando diz que talvez possamos compreender que a docência com o sujeito que possui deficiências sugere ser necessário que nos aventuraremos por uma "experimentação conceitual nova" ( p. 97), em uma relação com um outro estranho e muito diferente de nós, que nos faça passar por uma experiência estética (PAGNI, 2015, p. 99).

Com isso queremos dizer que a experiência nos processos de inclusão pode representar um outro olhar sobre os sujeitos com deficiência, e ao mesmo tempo permitir o desprendimento dos "preconceitos e da racionalidade técnica que governa as práticas ditas inclusivas" (PAGNI, 2015, p. 99), que tendem a normalizá-los e impedir que possam ser o que são, como condição para que a convivência seja possível.

\section{ALGUMAS PALAVRAS FINAIS}

Nosso objetivo com essa escrita era refletir sobre a formação docente que o Curso Normal está proporcionando a seus/suas alunos/as em relação à inclusão escolar. Para isso, olhamos para o seu currículo, em especial para os documentos norteadores e as práticas pedagógicas de docência realizadas pelos/as alunos/as. Para obtermos os efeitos do processo de formação produzido pelo Curso Normal buscamos as reflexões produzidas pelos/as alunos/as nos relatórios das Práticas Pedagógicas, desenvolvidas nas turmas dos anos iniciais e da educação infantil que possuíam alunos com deficiências. Nessas reflexões, encontramos compreensões diferentes acerca da inclusão das crianças com deficiências: uma que reduz a anormalidade à incapacidade; e outra, que nos possibilitou identificar marcas de uma sensibilização que se transformaram em experiência. São 
perspectivas diferentes para compreender a inclusão das crianças com deficiências na escola comum e (re)pensar seu currículo.

Essas perspectivas indicam que o "ensaio" da docência que o Curso Normal está proporcionando pelas suas intenções curriculares, está produzindo um encontro com o outro, que provoca reflexões sobre como ensinar e viver com o outro que possui deficiência. Segundo Gallo (2008, p.1), a educação é marcada por encontros, porém ele nos alerta dizendo que só há "encontro" na educação quando o outro pode ser outro. Assim, também podemos dizer que a inclusão escolar só pode ser inclusiva (sendo redundante) se afastar-se de intenções e práticas normalizadoras, que tendem a transformar o outro segundo um "modelo de normalidade", e aceitar o outro com deficiência considerando suas potencialidades, e não somente suas limitações.

Para isso, há que se pensar em currículos formativos que problematizem a visão normalizadora preponderante na educação, a qual tende conduzir todos em direção à "normalidade", adequando e conformando-os à modelos educativos e também de ensino. Talvez, apostando em currículos que se constituam a partir da experiência vivida no encontro com o outro, seja possível produzir possibilidades para reconhecer a singularidade, e nela a deficiência, não como um "defeito", não como um "erro" a ser corrigido, a ser normalizado, mas como uma outra forma de viver e de se relacionar com o mundo, seja nos processos de aprendizagem, seja no convívio entre os diferentes sujeitos. Essa compreensão sobre o outro deficiente será possível pela experiência que vivermos em nós, pela nossa capacidade de transformação, de abandonar o olhar pedagógico da inclusão sobre o outro com a intenção de corrigi-lo, de normalizá-lo e de fazer dele o que desejamos que seja. 


\section{REFERÊNCIAS}

BRASIL. Decreto-lei 8.530/46, de 2 de janeiro de 1946. Lei Orgânica do Curso Normal. Diário Oficial da União. Disponível em: <http://www.planalto.gov.br/ccivil_03/decreto-lei/1937-1946/Del8530.htm>. Acesso em: 10 maio 2018.

Parecer CNE/CEB 13, de 03 de Junho de 2009. Diretrizes operacionais para o AEE na Educação Básica, modalidade educação especial, p. 278-281. In: BRASIL. Ministério da Educação. Diretrizes Curriculares Nacionais Gerais para a Educação Básica: diversidade e inclusão. Secretaria da Educação Continuada, Alfabetização, Diversidade e Inclusão. Brasília, DF, 2013. Disponível em: <http://portal.mec.gov.br/docman/julho-2013-pdf/13677diretrizes-educacao-basica-2013-pdf/file>. Acesso em: 20 jan. 2018.

Lei 13.415, de 16 fev. 2017. Institui Política de Fomento à Implementação de Escolas de Ensino Médio em Tempo Integral. Diário Oficial da União, Brasília, 17 fev. 2017. Disponível em: <http://www.planalto.gov.br/ ccivil_03/ ato2015-2018/2017/lei/113415.htm>. Acesso em: 10 maio 2018.

FOUCAUlT, Michel. Segurança, Território e População: Curso Collège de France. São Paulo: Martins Fontes, 2008.

Os anormais: Curso no Collège de France (1974-1975). São Paulo: Martins Fontes, 2010.

GALLO, Sílvio. Eu, o outro e tantos outros: educação, alteridade e filosofia da diferença. In: CONGRESSO INTERNACIONAL DO COTIDIANO: DIÁLOGOS SOBRE DIÁLOGOS, 2008, Rio de Janeiro. Anais... Rio de Janeiro: UFF, 2008. Disponível em: <http://www.grupodec.net.br/wp-content/uploads/2015/10/GalloEuOutro Outros.pdf>. Acesso em: 10 maio 2015.

Base Comum Curricular: um instrumento da biopolítica. Cadernos IHU on-line, n. 516, p. 37-41, São Leopoldo: UNISINOS, 2017. Disponível em: <http://www.ihuonline.unisinos.br/artigo/7159-edicao-516-versao-parafolhear>. Acesso: 20 abril 2018.

LARROSA, Jorge. Experiência e alteridade em educação. Revista Reflexão e Ação, Santa Cruz do Sul, v.19, n. 2, p. 04-27, jul./dez. 2011.

Tremores: escritos sobre experiências. Belo Horizonte: Autêntica, 2017.

LARROSA, Jorge; KOHAN, Walter. Apresentação. In: MASSCHELEIN, Jan; SIMONS, Maarten. Em defesa da escola: uma questão pública. 2. ed. Belo Horizonte: Autêntica, 2014.

PAGNI, Pedro A. Diferença, subjetivação e educação: um olhar outro sobre a inclusão escolar. Pro-posições. São Paulo: UNICAMP, v. 26, n. 1 (76), p. 87-103, jan./abr. 2015.

PROJETO POLÍTICO-PEDAGÓGICO. Instituto Estadual de Educação Visconde de Cairu. Santa Rosa, 2017.

PLANO DE ESTUDOS. Instituto Estadual de Educação Visconde de Cairu. Santa Rosa, 2017.

RIGO, Neusete M. Inclusão e formação dos professores: como compreender e o que fazer com as crenças que temos? In: BONOTTO, D. de L.; SANTOS, E. G. dos S.; WENZEL, Judite S. (Orgs.). Movimentos formativos: caminhos e perspectivas na formação de professores. 1ed. Cerro Largo: Polimpressos. p. 31-51, 2015.

RIO GRANDE DO SUL. Secretaria Estadual da Educação. Caderno Pedagógico 1. A educação especial na perspectiva da educação inclusiva: diretrizes orientadoras para a rede estadual do ensino do Rio Grande do Sul. 2014.

ROMANELLI, Otaíza de O. História da Educação no Brasil. 7. ed. Petrópolis, RJ: Vozes, 1985.

TARDIF. Maurice. Saberes docentes e formação profissional. 9. ed. Petrópolis, RJ: Vozes, 2008.

O eterno desafio da valorização docente. Cadernos IHU on-line, n. 516, p. 62-64, São Leopoldo: UNISINOS, 2017. Disponível em: <http://www.ihuonline.unisinos.br/artigo/7159-edicao-516-versao-para-folhear>. Acesso: 20 abr. 2018 . 


\section{RESUMO}

Este artigo apresenta resultados de uma pesquisa sobre o currículo do Curso Normal em relação à inclusão escolar protagonizada a partir da Política Nacional de Educação Especial na Perspectiva da Educação Inclusiva/2008, na educação básica. O objetivo desse estudo é refletir sobre a formação docente para a inclusão escolar proporcionada pelo Curso Normal. A metodologia possui uma abordagem qualitativa e utiliza a análise de documentos pedagógicos da escola - Projeto Político-Pedagógico (PPP) e Planos de Estudos (PE) do Curso Normal - e de relatórios das Práticas Pedagógicas (PP) realizadas pelos/as alunos/as do curso, em turmas com alunos com deficiências, em escolas comuns. Como ferramentas analíticas dos dados levantados são utilizados os conceitos de experiência (Larrosa, 2011; 2017) e de normalidade/anormalidade (Foucault, 2008). Dessa análise, constituíram-se duas perspectivas em relação à inclusão das crianças com deficiências para a discussão dos dados: a) a anormalidade como incapacidade; e b) a experiência como possibilidade para o ensino e para a convivência com o sujeito com deficiências. Os resultados apresentam por um lado, que apesar dos esforços da escola para construir um currículo que proporcione uma formação inicial fundamentada em princípios inclusivos, a visão de normalidade é referência nas reflexões dos/as alunos/as do Curso Normal em relação à inclusão das crianças com deficiências na escola comum. Por outro lado, também se observa uma experiência vivida que indica possibilidades que se afastam de intenções que tendem corrigir ou normalizar o sujeito com deficiência.

Palavras-chave: Formação inicial de professores. Práticas Pedagógicas. Inclusão escolar.

\section{INITIAL DEGREE OF TEACHERS AT HIGH SCHOOL LEVEL (NORMAL COURSE) AND SCHOOL INCLUSION}

\section{ABSTRACT}

This article presents the results of a research on the curricular grade of the Normal Course in relation to the school inclusion carried out from the National Policy of Special Education in the Perspective of Inclusive Education / 2008, in basic education. The aim of this study is to reflect on the teacher preparation for the school inclusion provided by the Normal Course. The methodology has a qualitative approach and uses the analysis of pedagogical documents of the school - Political-Pedagogical Project (PPP) and Study Plans (SP) of the Normal Course - and reports of the Pedagogical Practices (PP) carried out by the students the course, in classes with students with disabilities, at ordinary schools. As analytical tools of the data collected are used the concepts of experience (Larrosa, 2011; 2017) and normality / abnormality (Foucault, 2008). From this analysis, two perspectives regarding the inclusion of children with disabilities were constituted, for the discussion of data: a) the abnormality as incapacity; and b) the experience as a possibility for teaching and for living with the person with disabilities. The results show, on the one hand, that despite the school's efforts to construct a curricular grade that provides an initial preparation based on inclusive principles, the normality vision is a reference in the reflections of the students of the Normal Course in relation to the inclusion of children with disabilities at the ordinary school. On the other hand, there is also a lived experience that indicates possibilities that deviate from intentions that tend to correct or normalize the disabled child.

Keywords: Initial teacher degree. Pedagogical practices. School inclusion.

\section{LA FORMACIÓN INICIAL DE PROFESORES EN NIVEL MÉDICO (CURSO NORMAL) Y LA INCLUSIÓN ESCOLAR}

\section{RESUMEN}

Este artículo presenta resultados de una investigación sobre el currículo del Curso Normal en relación a la inclusión escolar protagonizada a partir de la Política Nacional de Educación Especial en la Perspectiva de la Educación Inclusiva / 2008, en la educación básica. El objetivo de este estudio es reflexionar sobre la formación docente para la inclusión escolar proporcionada por el Curso Normal. La metodología tiene un abordaje cualitativo y utiliza el análisis de documentos pedagógicos de la escuela - Proyecto PolíticoPedagógico (PPP) y Planes de Estudios (PE) del Curso Normal - y de informes de las Prácticas pedagógicas (PP) realizadas por los / as alumnos / as del curso, en grupos con alumnos con discapacidades, en escuelas 
comunes. Como herramientas analíticas de los datos levantados se utilizan los conceptos de experiencia (Larrosa, 2011, 2017) y de normalidad / anormalidad (Foucault, 2008). De este análisis, se constituyeron dos perspectivas en relación a la inclusión de los niños con discapacidades, para la discusión de los datos: a) la anormalidad como incapacidad; y b) la experiencia como posibilidad para la enseñanza y para la convivencia con el sujeto con deficiencias. Los resultados presentan por un lado, que a pesar de los esfuerzos de la escuela para construir un currículo que proporcione una formación inicial fundamentada en principios inclusivos, la visión de normalidad es referencia en las reflexiones de los / las alumnos / as del Curso Normal en relación a la inclusión de los niños con deficiencias en la escuela común. Por otro lado, también se observa una experiencia vivida que indica posibilidades que se alejan de intenciones que tienden a corregir o normalizar al sujeto con discapacidad.

Palabras-clave: Formación inicial de profesores. Prácticas pedagógicas. Inclusión escolar. 